\title{
Erratum to: Role of PET/CT in malignant pediatric lymphoma
}

\author{
Raef Riad $^{1}$ • Walid Omar ${ }^{1}$ Magdy Kotb ${ }^{4} \cdot$ Magdy Hafez $^{1}$ - Iman Sidhom ${ }^{2}$ • \\ Manal Zamzam ${ }^{2,7} \cdot \operatorname{Iman}_{\text {Zaky }}{ }^{3}$ Hussein Abdel-Dayem ${ }^{5,6}$
}

Published online: 6 January 2017

(C) Springer-Verlag Berlin Heidelberg 2017

Erratum to: European Journal of Nuclear Medicine and Molecular Imaging 37(2): 319-329

DOI: $10.1007 / \mathbf{s 0 0 2 5 9 - 0 0 9 - 1 2 7 6 - 9}$

The sixth author, Manal Zamzam, would like to add an affiliation which is presented here.

The online version of the original article can be found at http://dx.doi. org/10.1007/s00259-009-1276-9

Hussein Abdel-Dayem

husseinad@aol.com

1 Department of Nuclear Medicine, Children's Cancer Hospital $(\mathrm{CCH})$, Cairo University, Cairo, Egypt

2 Department of Pediatric Oncology, Children's Cancer Hospital $(\mathrm{CCH})$, Cairo University, Cairo, Egypt

3 Department of Radio-diagnosis, Children's Cancer Hospital (CCH), Cairo University, Cairo, Egypt

4 Department of Nuclear Medicine, National Cancer Institute, Cairo, Egypt

5 Department of Radiology, Nuclear Medicine Section, St. Vincent's Catholic Medical Centers of New York, New York Medical College, Valhalla, NY, USA

6 Department of Radiology, New York Medical College, Nuclear Medicine Service, St. Vincent's Catholic Medical Centers of New York, 170 West 12th Street, Cr. 327, New York, NY 10011, USA

7 National Cancer Institute, Cairo University, Cairo, Egypt 